\title{
Glucocorticoid receptor gene inactivation in dopamine-innervated areas selectively decreases behavioral responses to amphetamine
}

\section{Sébastien Parnaudeau ${ }^{1,2,3,4 \dagger}$, Marie-louise Dongelmans ${ }^{1,2,3 \xi}$, Marc Turiault ${ }^{1,2,3 \xi}$, Frédéric Ambroggi ${ }^{5,6+\$}$, Anne-Sophie Delbes ${ }^{7}$, Céline Cansell ${ }^{7}$, Serge Luquet ${ }^{7}$, Pier-Vincenzo Piazza ${ }^{5 * 7}$, François Tronche ${ }^{1,2,3} *^{* *}$ and Jacques Barik ${ }^{1,2,3,8 * \neq \neq}$}

\author{
' UMR 7224 CNRS, Physiopathologie des Maladies du Système Nerveux Central, "Gene Regulation and Adaptive Behaviors" Group, Paris, France \\ 2 INSERM, UMRs 952, Physiopathologie des Maladies du Système Nerveux Central, Paris, France \\ ${ }^{3}$ Université Pierre et Marie Curie, Physiopathologie des Maladies du Système Nerveux Central, Paris, France \\ ${ }^{4}$ Department of Psychiatry, Columbia University, New York, NY, USA \\ ${ }^{5}$ Pathophysiology of Addiction, Institut National de la Santé et de la Recherche Médicale, U862, NeuroCentre Magendie, Bordeaux Cedex, France \\ ${ }^{6}$ Department of Neurology, Center for Integrative Neuroscience and the Ernest Gallo Clinic and Research Center, University of California at San Francisco, San \\ Francisco, CA, USA \\ 7 Unité de Biologie Fonctionnelle et Adaptative, Sorbonne Paris Cité, UMR 8251 CNRS, Université Paris Diderot, Paris, France \\ 8 Institut de Pharmacologie Moléculaire et Cellulaire, UMR 7275, Valbonne, France
}

\section{Edited by:}

Rainer Spanagel, Central Institute of

Mental Health, Germany

Reviewed by:

Gregg Stanwood, Vanderbilt

University, USA

Ainhoa Bilbao, Central Institute of

Mental Health, Germany

\section{*Correspondence:}

Pier-Vincenzo Piazza, Pathophysiology of Addiction, Institut National de la

Santé et de la Recherche Médicale

U862, NeuroCentre Magendie,

147 Rue Léo Saignat, 33077 Bordeaux

Cedex, France

e-mail: pier-vincenzo.piazza@inserm.fr;

François Tronche, Université Pierre et

Marie Curie-Paris 06, F-75252 Paris

Cedex 5, France

e-mail: francois.tronche@upmc.fr;

Jacques Barik, Institut de

Pharmacologie Moléculaire et

Cellulaire, 660 Route des Lucioles,

Sophia Antipolis, 06560 Valbonne,

France

e-mail: barik@ipmc.cnrs.fr

\section{${ }^{\dagger}$ Present address:}

Sébastien Parnaudeau, Department of Psychiatry, Columbia University, New York, NY, USA;

Frédéric Ambroggi, Department of

Neurology, Center for Integrative

Neuroscience and the Ernest Gallo

Clinic and Research Center, University

of California at San Francisco, San

Francisco, CA, USA;

Jacques Barik, Institut de

Pharmacologie Moléculaire et

Cellulaire, Valbonne, France.

¥Pier-Vincenzo Piazza, François Tronche

and Jacques Barik are co-last authors.

$\S$ These authors have contributed

equally to this work.
The meso-cortico-limbic system, via dopamine release, encodes the rewarding and reinforcing properties of natural rewards. It is also activated in response to abused substances and is believed to support drug-related behaviors. Dysfunctions of this system lead to several psychiatric conditions including feeding disorders and drug addiction. These disorders are also largely influenced by environmental factors and in particular stress exposure. Stressors activate the corticotrope axis ultimately leading to glucocorticoid hormone (GCs) release. GCs bind the glucocorticoid receptor (GR) a transcription factor ubiquitously expressed including within the meso-cortico-limbic tract. While GR within dopamine-innervated areas drives cocaine's behavioral responses, its implication in responses to other psychostimulants such as amphetamine has never been clearly established. Moreover, while extensive work has been made to uncover the role of this receptor in addicted behaviors, its contribution to the rewarding and reinforcing properties of food has yet to be investigated. Using mouse models carrying $G R$ gene inactivation in either dopamine neurons or in dopamine-innervated areas, we found that GR in dopamine responsive neurons is essential to properly build amphetamine-induced conditioned place preference and locomotor sensitization. c-Fos quantification in the nucleus accumbens further confirmed defective neuronal activation following amphetamine injection. These diminished neuronal and behavioral responses to amphetamine may involve alterations in glutamate transmission as suggested by the decreased MK801-elicited hyperlocomotion and by the hyporeactivity to glutamate of a subpopulation of medium spiny neurons. In contrast, GR inactivation did not affect rewarding and reinforcing properties of food suggesting that responding for natural reward under basal conditions is preserved in these mice.

Keywords: glucocorticoid receptor, dopamine pathway, glutamate, amphetamine, food reward, motivation 


\section{INTRODUCTION}

Reward processing involves the meso-cortico-limbic system, which includes dopamine midbrain neurons and their projections to the caudate putamen $(\mathrm{CPu})$, the nucleus accumbens (NAc), and the prefrontal cortex (PFC). Both addictive drugs and natural rewards act on these brain circuits that are likely to have evolved to motivate vital behaviors, including eating (Kelley and Berridge, 2002). Indeed, most drugs of abuse food rewards elicit an increase in DA release within the NAc (Di Chiara and Imperato, 1988; Hernandez and Hoebel, 1988) thought to participate to the encoding of rewarding and reinforcing properties of food rewards and addictive substances.

Vulnerability to abused drugs varies from one person to another. This interindividual variability most probably relies on both genetic and environmental factors, including stress exposure (Sinha, 2001). Similarly, stress exposure has also been shown to affect food intake and has been associated with feeding disorders (Torres and Nowson, 2007). Stress response triggers a large set of physiological reactions, including the activation of the hypothalamo-pituitary-adrenal (HPA) axis, ultimately leading to the secretion of glucocorticoids (GCs) by the adrenal gland in the blood flow. GCs activate two related nuclear receptors, the glucocorticoid receptor (GR) ubiquitously expressed, including within neurons of the reward circuitry, and the mineralocorticoid receptor $(\mathrm{MR})$ restricted to more discrete brain regions. Both act as transcription factors, in the nucleus, to control gene expression and, at the membrane, participate to the rapid modulation of neuronal excitability and intracellular signaling cascades. During stress response MR is involved in the appraisal of novel situations whereas GR facilitates the consolidation of stress-related information (Groeneweg et al., 2011).

Clinical studies, supported by compelling animal data, underlie the central role of GCs in modulating responses to abused drugs and feeding behaviors (Marinelli and Piazza, 2002; Dallman et al., 2004; Sinha et al., 2006; Adam and Epel, 2007). For example, surgical suppression of circulating GCs in rats decreases locomotor responses to psychostimulants, an effect rescued by hormone replacement (Marinelli et al., 1997). Similarly, adrenalectomy have been shown to block the increase of fat intake observed after fasting in rat and this behavior is restored after corticosterone treatment (Castonguay, 1991). In addition, chronic GCs treatments in rats have been shown to impair goal-directed behavior as well as motivation to obtain food reward (Gourley et al., 2012).

We previously developed $\mathrm{GR}^{\mathrm{D} 1 \mathrm{Cre}}$ and $\mathrm{GR}^{\text {DATCre }}$ mouse models. The $\mathrm{GR}^{\mathrm{D} 1 \mathrm{Cre}}$ mice are deprived of GR in most of medium spiny neurons and neurons of the basal layers of the cortex (hereafter described as dopaminoceptive neurons) while $\mathrm{GR}^{\mathrm{DATC} e}$ mice are deprived of GR in dopamine neurons (Ambroggi et al., 2009; Barik et al., 2013). The absence of GR in dopaminoceptive but not dopamine-releasing neurons diminished sensitizing, rewarding, and reinforcing effects of cocaine (Ambroggi et al., 2009; Barik et al., 2010). In striking contrast, we showed that morphine responses in both models remained unaltered (Barik et al., 2010) although stress facilitates opiates effects (Deroche et al., 1995). While these results suggest a GR-dependent dichotomy for the regulation of psychostimulant and opiate responses, such hypothesis still needs to be validated, as GR involvement in responses to other psychostimulant drugs such as amphetamine has never been clearly established. In addition, while extensive work has been made to uncover the role of this receptor in drugs of abuse-related behaviors, its potential contribution in responses to food rewards and the neuronal population that may be involved have yet to be investigated. We therefore, examined the ability of GR along the DA pathway to modulate behavioral responses to amphetamine and food rewards. We demonstrated that GR in dopaminoceptive neurons selectively modulated behavioral and molecular responses to amphetamine without altering rewarding and reinforcing properties of food rewards.

\section{MATERIALS AND METHODS \\ ANIMAL BREEDING AND DRUG TREATMENTS}

$\mathrm{Nr} 3 \mathrm{cl}(G R)$ gene inactivation was selectively targeted in dopaminoceptive $\quad\left(\mathrm{Nr} 3 \mathrm{cl}^{\text {loxP}} / \mathrm{loxP} ;(\mathrm{Tg}) \mathrm{D} 1 \mathrm{aCre}\right.$ (Lemberger et al., 2007), hereafter designed $\mathrm{GR}^{\mathrm{D} 1 \mathrm{Cre}}$ ) or dopamine (Nr3cl ${ }^{\text {loxP/loxP}}$;(Tg)BAC-DATiCrefto (Turiault et al., 2007), hereafter designed $\mathrm{GR}^{\mathrm{DATCre}}$ ) neurons as described in Ambroggi et al. (2009). Experimental animals were obtained by mating $\mathrm{Nr} 3 \mathrm{cl}^{\text {loxP/loxP }}$ females with either $\mathrm{Nr} 3 \mathrm{cl}^{\text {loxP/loxP}}$; Tg:D1aCre or $\mathrm{Nr} 3 \mathrm{cl}^{\text {loxP/loxP}}$; (Tg)BAC-DATiCrefto mice. Half of the progeny were mutant animals, the other half were control littermates. Animals were bred and raised under standard animal housing conditions, at $22^{\circ} \mathrm{C}, 55-65 \%$ humidity, with a 12 -h light/dark cycle $(7 \mathrm{am} / 7 \mathrm{pm})$ and free access to water and a rodent diet. All experiments were performed in accordance with French (Ministère de l'Agriculture et de la Forêt, 87-848) and the European Directive 2010/63/UE and the recommendation 2007/526/EC for care of laboratory animals. Mice were 2-4 month old males and backcrossed for more than 8 generations on C57BL/ 6 genetic background. All the experiments have been performed within the hours preceding or encompassing the beginning of dark phase $(7 \mathrm{pm})$, when corticosterone levels are elevated (Le Minh et al., 2001). The behavioral sensitization experiments have been carried out from $6 \mathrm{pm}$ to $9 \mathrm{pm}$; The $\mathrm{CPP}$ experiments from $7 \mathrm{pm}$ to $11 \mathrm{pm}$ and the food progressive ratio (PR) experiment were performed from $4 \mathrm{pm}$ to $6 \mathrm{pm}$. All drugs were dissolved in saline $0.9 \%$. D-amphetamine (freebase; Sigma-Aldrich, Saint-Quentin Fallavier, France), SKF81297 (salt; Tocris Cookson, Bristol, UK), and MK801 (salt; Tocris Cookson, Bristol, UK) were administered intraperitoneally (ip).

\section{LOCOMOTOR ACTIVITY AND SENSITIZATION}

Locomotor activity and sensitization were performed as described in Barik et al. (2010). Briefly, locomotor activity was assessed in circular chamber ( $4.5-\mathrm{cm}$ width, $17-\mathrm{cm}$ external diameter) crossed by four infrared captors $(1.5 \mathrm{~cm}$ above the base $)$ placed at every $90^{\circ}$ (Imetronic, Bordeaux, France). The locomotor activity was counted when animals interrupted two successive beams and thus, had travelled a quarter of the circular corridor. Mice were habituated to the apparatus for $3 \mathrm{~h}$, for 3 consecutive days, and received a saline injection on days 2 and 3 . To assess the response to SKF81297 or MK801, on day 4 mice were placed in the apparatus for $90 \mathrm{~min}$ before receiving an acute injection of SKF81297 (1.5 or $3 \mathrm{mg} / \mathrm{kg})$ or MK801 $(0.2 \mathrm{mg} / \mathrm{kg})$. In the case of amphetamine-induced locomotor sensitization, from day 4 to 8 , 
mice were daily treated with amphetamine or saline after a $90 \mathrm{~min}$ habituation to the apparatus. Following 8 days of withdrawal, mice received an acute challenge of amphetamine. The locomotor activity post-injection was acquired for $1 \mathrm{~h}$. For acute drug responses data are recorded as $1 / 4$ turn per $5 \mathrm{~min}$. For clarity reason, data are presented every $10 \mathrm{~min}$. For locomotor sensitization, data are presented as the sum of activity over $1 \mathrm{~h}$.

\section{CONDITIONED PLACE PREFERENCE}

The conditioned place preference (CPP) apparatus consisted of two chambers $(20 \times 20 \times 25 \mathrm{~cm})$ with distinct visual and tactile cues connected by a neutral area. On day 1 (pre-conditioning), mice were placed in the neutral area allowed to freely explore the apparatus for $18 \mathrm{~min}$. The time spent in each chamber was measured. On days 2, 4, 6, and 8, amphetamine-paired mice received an amphetamine injection ( 1 or $2 \mathrm{mg} / \mathrm{kg}$ ) and were confined to one chamber for $25 \mathrm{~min}$. On days 3, 5, 7, and 9, amphetaminepaired mice received saline in the opposite chamber and were also confined for $25 \mathrm{~min}$. Saline-paired animals received saline in both chambers. To examine food-induced CPP, mice had limited access to chow pellet in their home-cage for a week, to stabilize their bodyweight to $85 \%$ of their original weight. Conditioning for food was similar to that of amphetamine. Food-paired mice received a chow pellet ( $1 \mathrm{~g}$; standard food $\mathrm{CPP}$ ) or chocolate with cereals ("chocapic," Nestlé, 0.5 g; palatable food CPP) in the paired chamber on days 2, 4, 6, 8 and confined for $30 \mathrm{~min}$. On days $3,5,7,9$, mice were confined to the other, unpaired, chamber but had no access to food. No food-paired mice were alternatively placed in each chamber with no access to food at any time. During the post-conditioning (day 10), mice, in absence of any reward, were allowed to freely explore both chambers for $18 \mathrm{~min}$. The CPP scores were expressed as the increase of time spent in the paired chamber between the post- and the pre-conditioning sessions.

\section{PROGRESSIVE RATIO FOR FOOD \\ Apparatus}

The PR experiment took place in 12 home cages containing an operant conditioning wall $(24 \times 28 \times 28 \mathrm{~cm}$, Operant Behavior System, TSE, Bad Homburg, Germany). The operant wall had two retractable levers, a food pellet dispenser delivering $20 \mathrm{mg}$ sucrose pellets with peanut butter flavor (GlaxoSmithKline, TestDiet, Richmond, IN, USA) and white light bulbs above the levers and in the dispenser. The operant walls were covered outside periods of training and testing. The boxes were covered with a layer of corn cob bedding and enriched with cotton nest pads. Water was available ad-libitum. During the period of habituation food (chow, SAFE, Augy, France) was also available ad-libitum.

\section{Habituation, Training, and Testing}

Mice were maintained at $85 \%$ of their initial body weight during training and testing. We tested 6 control and $6 \mathrm{GR}^{\mathrm{D} 1 \mathrm{Cre}}$ mice. During the habituation period ( 2 days) mice were placed in the operant boxes with ad-libitum access to food. The mice had continuously access to the operant wall and learnt to lever press for sucrose pellets under a fixed ratio 1 (FR1) schedule (i.e., a single press on the active lever resulted in the delivery of one sucrose pellet). Mice were trained on a FR1 schedule overnight. for 4 days. The FR1 schedule was followed by 6 days of PR schedule during which the cost of a reward is progressively increased for each following reward in order to determine the amount of work the mouse is willing to put into obtaining the reward. The response requirement increases incrementally according to a non-arithmetic progression: 1, 2, 2, 3, 3, 3, 4, 4, 4, $4,5, \ldots$ etc. and forms the following series: $1,2,4,6,9,12,15,19$, $23,27,31, \ldots$ etc. PR sessions were carried out once a day. One non-responding control mouse was excluded from the analysis. Breaking point values were defined as the last ratio completed by the animal followed by 15 min during which no additional reward was earned.

\section{IMMUNOHISTOCHEMISTRY}

Immunohistochemistry was performed as described in Barik et al. (2010). Briefly, mice were deeply anaesthetized with pentobarbital (Centravet, France) and transcardially perfused with cold phosphate buffer (PB: $0.1 \mathrm{M} \mathrm{Na}_{2} \mathrm{HPO}_{4} / \mathrm{NaH}_{2} \mathrm{PO}_{4}, \mathrm{pH}$ 7.4), followed by $4 \%$ PFA in PB. Brains were post-fixed overnight in 4\% PFA$\mathrm{PB}$. Free-floating vibratome sections $(30 \mu \mathrm{m})$ were rinsed twice with PBS (20 min) and incubated (30 min) in PBS-BT (PBS 0.5\% BSA, $0.1 \%$ Triton $\mathrm{X}-100$ ) with $10 \%$ normal goat serum (NGS). Sections were incubated $\left(4^{\circ} \mathrm{C}\right)$ in PBS-BT, $1 \%$ NGS, with rabbit anti-c-Fos (1:500, Abcam, Cambridge, MA) for $36 \mathrm{~h}$. Sections were rinsed in PBS and incubated $(2 \mathrm{~h})$ in goat anti-rabbit biotinylated secondary antibody (1:1000, Vector Laboratories, Burlingame, CA) in PBS-BT, 1\% NGS. PBS-rinsed sections were incubated in avidin-biotin-peroxydase complex (ABC reagent; Vector Laboratories, 1:1000) for $1 \mathrm{~h}$. Signal was revealed using the peroxidase-substrate-kit-DAB, as recommended by Vector Laboratories. Quantification of c-Fos immunopositive cells was done semi-automatically using Mercator Explora-Nova software (La-Rochelle, France). CPU and NAc regions were delineated according to Paxino's mouse brain atlas. For, drug-induced cFos expression, mice received an acute challenge of saline or amphetamine, and were perfused $1 \mathrm{~h}$ later.

\section{MICRO-IONTOPHORESIS AND IN VIVO RECORDINGS}

Electrophysiological recordings of NAc medium spiny neurons were performed during the diurnal phase. The experimenter was blind to the genotype during recordings. Mice were anesthetized with chloral hydrate $(5.0 \mathrm{mg} / \mathrm{kg}$, i.p.) and mounted in a stereotaxic apparatus. The lateral tail vein was catheterized to administer additional anesthetic or drugs. Body temperature was monitored and maintained with a heating pad at 36.5$37.0^{\circ} \mathrm{C}$. Standard electrophysiological procedures were employed. The electrode signal was amplified 2000 times with an AC high impedance amplifier, band pass filtered at $0.4-1 \mathrm{kHz}$ (Dagan 2400A, Minneapolis, MN), and digitized with an interface board at $10 \mathrm{kHz}$ (Digidata 1440A, Axon Instruments Inc., Foster City, CA) and fed to a computer for offline analysis.

For single unit recordings of NAc medium spiny neurons, five barrels manufactured electrodes (ASI instruments, Warren, MI) were pulled and broken to a tip diameter of $8-15 \mu \mathrm{m}$. The center barrel was filled with $2 \mathrm{M} \mathrm{NaCl}$ containing $1 \%$ Fast Green dye (impedance 2-6M $\Omega$ ) and was used to record neuronal activity. One side barrel (impedance 20-60 M $\Omega$ ) was 


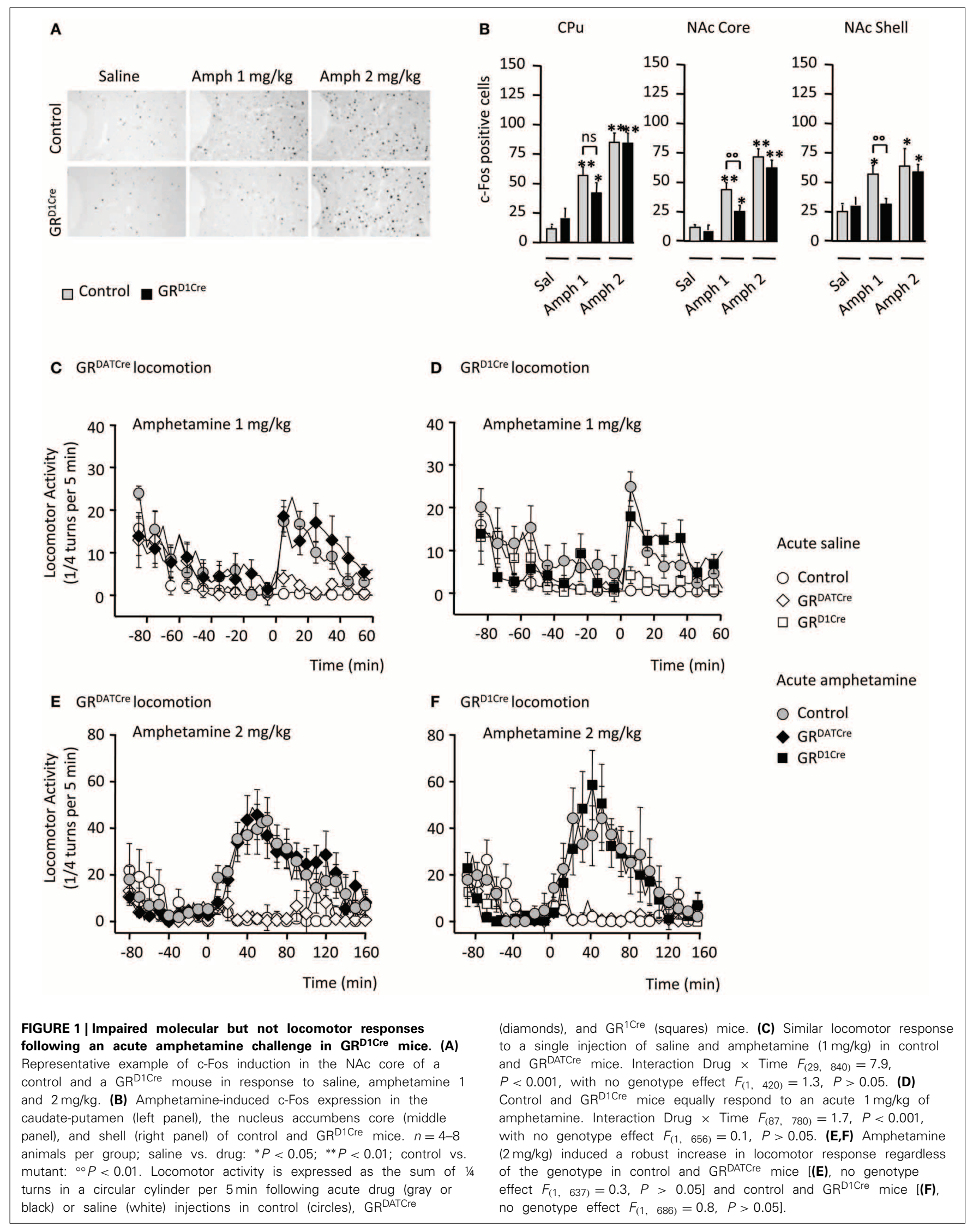


filled with $150 \mathrm{mM} \mathrm{NaCl}$ for automatic current balancing. The other barrels were filled with L-glutamate $(100 \mathrm{mM}, \mathrm{pH} 8)$, which was ejected as an anion. A retaining current (5-10 nA) was applied during non-ejection periods to minimize passive diffusion.

Electrodes were lowered in the NAc as followed: $\mathrm{AP}+1.1 /+1.7$, $\mathrm{L}+0.6 / 1.2$ and $\mathrm{DV}-3.9 /-5.0 \mathrm{~mm}$ from the cortical surface. Because most NAc neurons are quiescent in the basal state, glutamate was ejected by micro-iontophoresis while searching for neurons. Once a neuron was detected, the stability of the signal to noise ratio and waveform characteristics were assessed. Recorded neurons were identified as medium spiny neurons NAc neurons by their anatomical location and waveform durations comprised between 1.1 and $1.8 \mathrm{~ms}$ (White, 1996; Kish et al., 1999; Mallet et al., 2005). To generate current-response curves, glutamate was ejected by micro-iontophoresis using escalating currents applied in $15 \mathrm{~s}$ pulses interspersed with $15 \mathrm{~s}$ of non-ejection periods.

\section{STATISTICS}

Data are presented as means \pm s.e.m. Statistical analysis was carried out using Two-Way analysis of variance (ANOVA) for CPP, drug-elicited c-Fos induction. Acute locomotor responses and locomotor sensitization experiments were analyzed with ThreeWay ANOVA with repeated measures. Post-hoc Bonferroni's test or Dunnett's for multiple comparison tests were used when appropriate.

\section{RESULTS \\ ACUTE NEURONAL AND BEHAVIORAL RESPONSES TO AMPHETAMINE IN MICE DEPRIVED OF GR GENE WITHIN THE MESO-CORTICO-LIMBIC DOPAMINE SYSTEM}

We studied neuronal activation upon amphetamine response by quantifying c-Fos expression in mutant and control littermates. Consistent with previous findings (Moratalla et al., 1996), amphetamine ( 1 and $2 \mathrm{mg} / \mathrm{kg}$ ) elicited a significant increase in the number of c-Fos-positive cells within the $\mathrm{CPu}$ and the NAc core and shell of control animals (Figures 1A,B). This effect was significantly diminished within the NAc subdivisions and displayed a trend toward a decrease in the $\mathrm{CPu}$ when $\mathrm{GR}^{\mathrm{D} 1 \mathrm{Cr} e}$ mice were administered $1 \mathrm{mg} / \mathrm{kg}$ of the drug (Figures 1A,B). No significant genotype difference was observed when animals were administrated a higher dose $(2 \mathrm{mg} / \mathrm{kg})$ of amphetamine (Figures 1A,B). These results indicate a hyporesponsiveness of the NAc of $\mathrm{GR}^{\mathrm{D} 1 \mathrm{Cre}}$ mice to low doses of amphetamine.

In many species including rodents, psychostimulant injection triggers a typical increase in locomotor responses. Thus, locomotor activity of $\mathrm{GR}^{\mathrm{D} 1 \mathrm{Cre}}$ mice and their control littermates was measured following acute amphetamine administration. To ascertain the lack of involvement of GR in dopamine-releasing neurons we also examined responses in $\mathrm{GR}^{\mathrm{DATCre}}$ mice and their respective controls. While saline injection failed to produce any locomotor hyperactivity, amphetamine increased locomotor activity in control mice with a stronger response at $2 \mathrm{mg} / \mathrm{kg}$ compared to $1 \mathrm{mg} / \mathrm{kg}$ (Figures $\mathbf{1 C}-\mathbf{F}$ ). The locomotor response to single amphetamine injection was the same in both $\mathrm{GR}^{\text {DATCre }}$ (Figures 1C,D) and $\mathrm{GR}^{\mathrm{D} 1 \mathrm{Cre}}$ mice (Figures 1E,F) compared to their respective control littermates, for both doses tested. Thus,

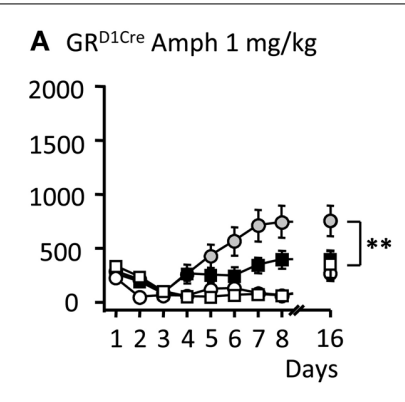

B GR ${ }^{\text {DATCre }}$ Amph $1 \mathrm{mg} / \mathrm{kg}$

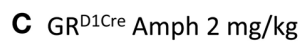
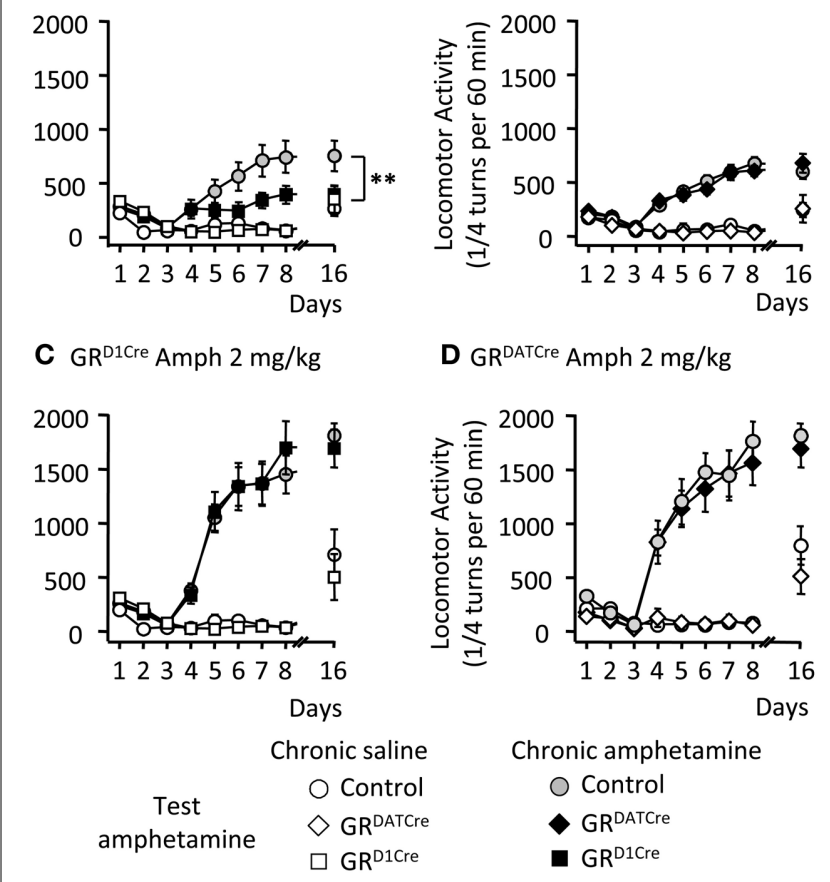

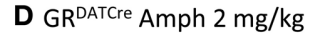

FIGURE 2 | The locomotor sensitization to low dose of amphetamine is selectively abolished in $\mathbf{G R}^{\mathbf{D} 1 \text { Cre }}$ mice. Locomotor activity is expressed as the sum of $1 / 4$ turns in a circular cylinder per hour following repeated drug or saline injections. (A) Locomotor sensitization to $1 \mathrm{mg} / \mathrm{kg}$ amphetamine daily injections in control (gray circles) and GR $\mathrm{R}^{\mathrm{D} 1 \mathrm{Cre}}$ mice (black squares). White circles and white squares represent control and $\mathrm{GR}^{\mathrm{D} 1 \mathrm{Cre}}$ mice, respectively, which received daily injections of saline followed by a challenge injection of amphetamine $1 \mathrm{mg} / \mathrm{kg}$ on the test day. Amphetamine $(1 \mathrm{mg} / \mathrm{kg})$ induced locomotor sensitization that was abolished in $\mathrm{GR}^{\mathrm{D} 1 \mathrm{Cre}}$ mice at day 16; interaction Genotype $\times$ Treatment $F_{(1,28)}=5.2$; saline vs. drug: $P<0.01$; control vs. mutant: ${ }^{* *} P<0.01$. (B) Locomotor sensitization to $1 \mathrm{mg} / \mathrm{kg}$ amphetamine daily injections in control (gray circles) and GR ${ }^{\text {DATCre }}$ (black diamond) mice. White circles and white squares represent control and GR ${ }^{\text {DATCre }}$ mice, respectively, which received daily injections of saline followed by a challenge injection of amphetamine $1 \mathrm{mg} / \mathrm{kg}$ following an 8-day withdrawal period. Interaction Genotype $\times$ Treatment $F_{(1,33)}=0.16$; saline vs. drug: $P<0.001$; control vs. mutant: $P=0.6$. (C, D) are same than $(\mathbf{A}, \mathbf{B})$, respectively, but with $2 \mathrm{mg} / \mathrm{kg}$ amphetamine. $n=8-10$ per group. (C) Interaction Genotype $\times$ Treatment $F_{(1,36)}=1.72$; saline vs. drug: $P<0.001$; control vs. mutant: $P=0.67$. (D) Interaction Genotype $\times$ Treatment $F_{(1,37)}=0.27$; saline vs. drug: $P<0.001$; control vs. mutant: $P=0.21$.

the absence of GR in dopaminoceptive neurons does not alter the acute behavioral response to amphetamine.

\section{THE ABSENCE OF GR IN DOPAMINOCEPTIVE NEURONS DECREASES THE SENSITIVITY TO LOCOMOTOR SENSITIZING PROPERTIES OF AMPHETAMINE}

One of the key features of abused drugs is their ability to trigger locomotor sensitization (Vanderschuren and Pierce, 2010), i.e., a progressive and enduring augmentation in locomotor activity following repeated drug injection. We assessed the sensitizing properties of amphetamine in $\mathrm{GR}^{\mathrm{D} 1 \mathrm{Cre}}$ and $\mathrm{GR}^{\mathrm{DATCre}}$ mice, and respective control littermates. Five consecutive daily injections 
of amphetamine $(1 \mathrm{mg} / \mathrm{kg})$, but not saline, induced significant locomotor sensitization in control mice, which was still persistent following an 8-day withdrawal period (Figures $2 \mathbf{A , B}$ ). In contrast $\mathrm{GR}^{\mathrm{DiCre}}$ mice failed to develop locomotor sensitization (Figure 2A) whereas the absence of GR in dopamine neurons (GR ${ }^{\text {DATCre }}$ mice) had no effect (Figure 2B). When tested at a higher dose $(2 \mathrm{mg} / \mathrm{kg})$, amphetamine induced a more robust locomotor sensitization that was similar in both mutant lines and their respective control littermates (Figures 2C,D). Hence, GR within dopaminoceptive neurons is selectively required for enabling locomotor sensitization to low doses of amphetamine. This suggests that elevated doses of amphetamine are likely to provoke stronger molecular activations that hence may overcome GR's modulatory effects.

\section{THE ABSENCE OF GR IN DOPAMINOCEPTIVE NEURONS DECREASES THE SENSITIVITY TO REWARDING PROPERTIES OF AMPHETAMINE}

Repeated pairings of abused drugs in a specific environment triggers reward-associated memories (Kelley, 2004) thought to reflect changes in the motivational state of the subject (Bardo and Bevins, 2000). We next studied amphetamine CPP, a commonly employed context-dependent paradigm, to measure the effects of rewarding stimuli in GR mutant animals. On the preconditioning day, all four groups of animals spent similar amount of time in the two distinct chambers (Figure 3A). Pairing injections of 1 or $2 \mathrm{mg} / \mathrm{kg}$ of amphetamine produced a significant CPP in control mice (Figures 3B,C). Mirroring the results obtained for locomotor sensitization, these rewarding effects were abolished in $\mathrm{GR}^{\mathrm{D} 1 \mathrm{Cre}}$ mice at the lowest dose of amphetamine tested, but were not significantly different from controls when the dose was increased up to $2 \mathrm{mg} / \mathrm{kg}$ (Figure 3B). The absence of GR in pre-synaptic dopamine neurons had no effect as $\mathrm{GR}^{\mathrm{DATC} e}$ mice displayed normal CPP to $1 \mathrm{mg} / \mathrm{kg}$ amphetamine (Figure 3C).

\section{ABNORMAL LOCOMOTOR RESPONSE TO NMDA ANTAGONIST IN ABSENCE OF GR IN DOPAMINOCEPTIVE NEURONS}

In response to abused drugs, the increase of dopamine release within the $\mathrm{CPu}$ and NAc is thought to filter and selectively reinforce connections arising from excitatory corticostriatal projections (Bamford et al., 2004). Hence this dopamine/glutamate interaction is key to shape medium spiny neurons responsiveness at both electrophysiological and molecular levels, with a central implication of D1 dopamine receptors and NMDA glutamate receptors in these processes (Nicola et al., 2000; Pascoli et al., 2011). We therefore, examined whether GR gene inactivation within dopaminoceptive neurons could impact on dopamine and glutamate receptor functions that may explain the observed phenotype. To challenge D1 dopamine receptor, we injected SKF81297, a selective D1-like receptor agonist and measured subsequent locomotor responses. As previously reported (Corvol et al., 2007), acute systemic SKF81297 injection elicited hyperlocomotion in control animals (Figure 4A). At the 2 doses examined ( 1.5 and $3 \mathrm{mg} / \mathrm{kg}), \mathrm{GR}^{\mathrm{D} 1 \mathrm{Cre}}$ mice did not differ from their respective control littermates (Figure 4A) ruling out an impaired functionality of D1 dopamine receptors. To determine the state of glutamate transmission in $\mathrm{GR}^{\mathrm{D} 1 \mathrm{Cre}}$ mice, we then assessed the ability of MK801, a non-competitive NMDA antagonist, to elicit hyperlocomotion (Qi et al., 2008). Systemic injection of MK801 $(0.2 \mathrm{mg} / \mathrm{kg})$ triggered a robust hyperlocomotion in controls that was significantly decreased in mutant mice (Figure 4B). Therefore, this set of experiments suggests that the impaired glutamate response may play a role in the diminished response to amphetamine.

\section{DECREASED RESPONSIVENESS TO GLUTAMATE IN A SUBPOPULATION OF MEDIUM SPINY NEURONS WITHIN THE NUCLEUS ACCUMBENS OF GR $^{\text {D1CRE }}$ MICE}

Altered glutamatergic neurotransmission within the NAc might contribute to the impaired behavioral responses to amphetamine and MK801 as well as to the decrease of accumbal c-Fos induction observed in $\mathrm{GR}^{\mathrm{D} 1 \mathrm{Cre}}$ mice. To investigate the functional effects of GR inactivation on glutamatergic neurotransmission within the NAc, we analyzed the reactivity to glutamate of NAc medium spiny neurons. We performed in-vivo recordings of NAc medium spiny neurons coupled to glutamate micro-iontophoresis in control and $\mathrm{GR}^{\mathrm{D} 1 \mathrm{Cre}}$ mice. For each neuron, incremental glutamate ejection currents were applied until the neuron reached its maximal firing frequency. In control mice, the maximal frequencies observed were normally-distributed, ranging from 7 to $17 \mathrm{~Hz}$ (Figures 5A-C). In contrast in $\mathrm{GR}^{\mathrm{D} 1 \mathrm{Cre}}$ mice, the distribution was bimodal: one population had maximal frequencies in a range similar to that observed in control mice, whereas another population was shifted toward lower frequencies; these neurons were unable to fire above $6 \mathrm{~Hz}$. The analysis of the dose-response functions revealed that the $\mathrm{EC}_{50}$ was similar between controls, fast and slow neurons (Figure 5D). We found no evidence of anatomical segregation of fast and slow neurons; in particular, they were found equally in the core and the shell $(P>0.05)$. This experiment shows that GR positively controls the reactivity to glutamate of a subset of NAc medium spiny neurons.

\section{UNALTERED RESPONSES TO FOOD REWARDS IN GR ${ }^{\text {1CRE }}$ MICE}

As the processing of natural rewards and addictive drugs activate overlapping pathways, we sought to determine whether GR gene inactivation in dopaminoceptive neurons resulted in a general impairment of natural reward-seeking. As we did for amphetamine, we first tested control and mutant mice in two CPP experiments in response to normal (chow pellets) or palatable (chocolate) food. Mice were exposed for $30 \mathrm{~min}$ to either food in the paired chamber and spent the same amount of time, without food, in the opposite (unpaired) chamber on alternate days. Following 8 days of conditioning, the time increase in the paired chamber was used as an index of place preference. Both normal and palatable food elicited significant CPP in control animals. However, unlike our results with amphetamine, CPP remained unaltered in $\mathrm{GR}^{\mathrm{D} 1 \mathrm{Cre}}$ mice (Figures 6A,B respectively).

Next, as GR inactivation within dopaminoceptive neurons has been reported to decrease motivation for cocaine in a PR schedule (Ambroggi et al., 2009), we thus, tested motivation of $\mathrm{GR}^{\mathrm{D} 1 \mathrm{Cre}}$ mice to respond instrumentally for food rewards. During initial instrumental training, under a fixed-ratiol schedule, control and $\mathrm{GR}^{\mathrm{D} 1 \mathrm{Cre}}$ mice did not show significant differences in the number of responses (Figure 6C) and ate similar amount of pellets (control: $6.04 \pm 0.29 \mathrm{~g}, \mathrm{GR}^{\mathrm{D} 1 \mathrm{Cre}}: 6.3 \pm 0.23 \mathrm{~g}$ ). During 
A Pre-test, time in chambers

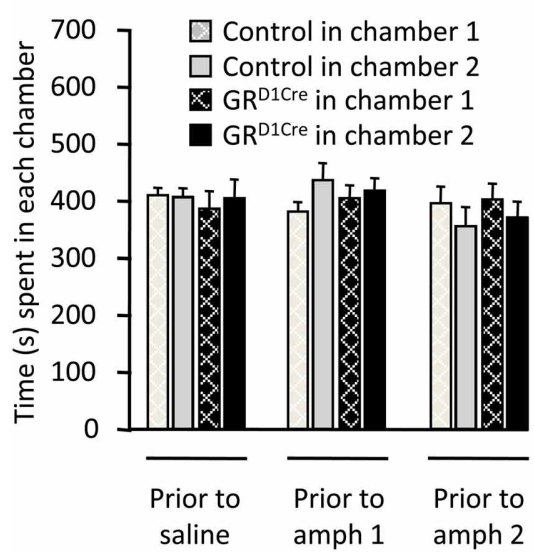

FIGURE 3 | GR ${ }^{\text {D1Cre }}$ mice show a decreased sensitivity to amphetamine rewarding properties. CPP scores represent the time difference between post-conditioning and pre-conditioning phases that mice spent in the reward-paired chamber. (A) Time spent in each chamber of the CPP apparatus by control (gray bars) and $\mathrm{GR}^{\mathrm{D} 1 \mathrm{Cre}}$ mice (black bars), during the pre-conditioning phase. (B) CPP to amphetamine 1 and $2 \mathrm{mg} / \mathrm{kg}$ in control
B Amph CPP, GR D1Cre

C Amph CPP, GR DATCre
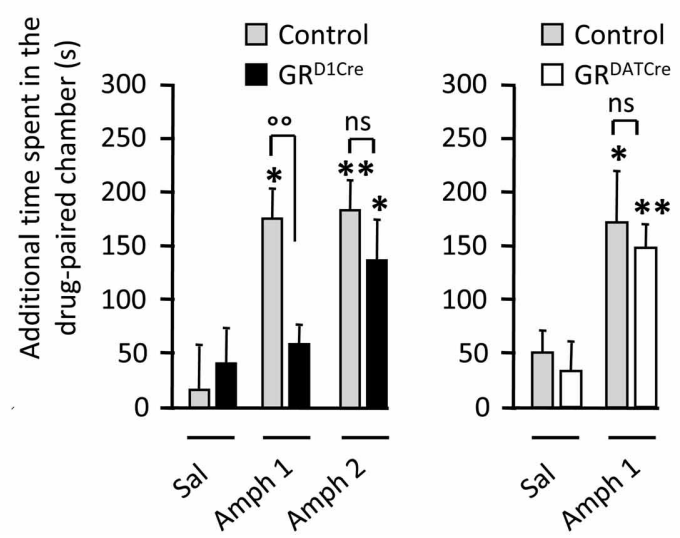

and $\mathrm{GR}^{\mathrm{D} 1 \mathrm{Cre}}$ mice. CPP induced by amphetamine $(1 \mathrm{mg} / \mathrm{kg})$ differed in control and $\mathrm{GR}^{\mathrm{D} 1 \mathrm{Cre}}$ mice. Interaction Drug $\times$ Genotype $F_{(1,39)}=4.5, P<0.05$. (C) Amphetamine (1 mg/kg)-induced comparable CPP in both control and GR ${ }^{\text {DATCre }}$ mice. No interaction Drug $\times$ Genotype $F_{(1,35)}=1.1, P>0.05$. ns: non-significant, ${ }^{*} P<0.05$; ${ }^{* *} P<0.01$; control vs. mutant: ${ }^{\circ} P<0.01$. $n=8-12$ mice per group.

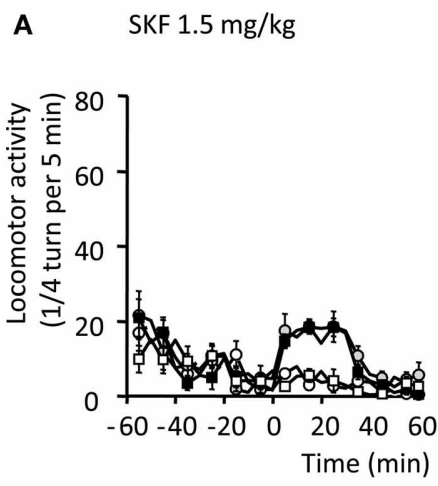

Control, saline
$\mathrm{SKF} 3.0 \mathrm{mg} / \mathrm{kg}$

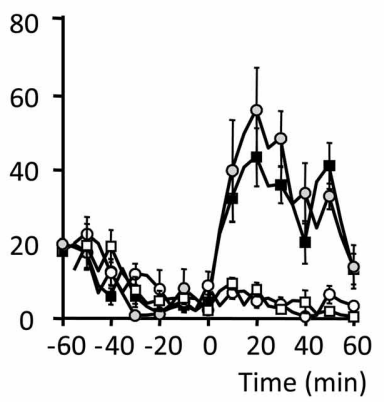

B $\quad$ MK801 $0.2 \mathrm{mg} / \mathrm{kg}$

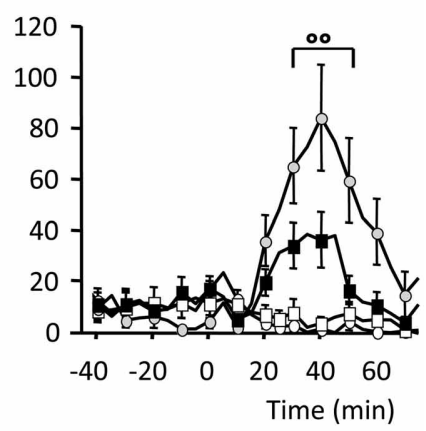

GR $\mathrm{R}^{\mathrm{1Cr}}$, drug
FIGURE 4 | Normal D1-like dopamine receptor agonist induced locomotor activity, but impaired MK801-elicited hyperlocomotion in $\mathbf{G R}^{\mathbf{D} 1 \mathrm{Cre}}$ mice. Locomotor responses are presented as $1 / 4$ turn per $5 \mathrm{~min}$. (A) Locomotor response to saline and SKF81297 $1.5 \mathrm{mg} / \mathrm{kg}$ (left panel) and $3 \mathrm{mg} / \mathrm{kg}$ (right panel) in control and $\mathrm{GR}^{\mathrm{D} 1 \mathrm{Cre}}$ mice. Interaction Drug $\times$ Time for SKF81297 at $1.5 \mathrm{mg} / \mathrm{kg}\left[F_{(17,714)}=10.3, P<0.001\right]$ and $3 \mathrm{mg} / \mathrm{kg}\left[F_{(17,714)}=9.4, P<0.001\right]$, but no interaction Drug $x$ Time $\times$ Genotype, $F_{(17,714)}=1.2, P>0.05$ and $F_{(17,714)}=0.8$, $P>0.05$, respectively. (B) MK801 elicited a stronger hyperlocomotion in control than $\mathrm{GR}^{\mathrm{D} 1 \mathrm{Cre}}$ mice, interaction Drug $\times$ Time $\times$ Genotype, $F_{(18,756)}=1.9, P<0.01 .{ }^{\circ} P<0.01$, control vs. mutant. $n=8-14$ mice per group. the learning phase of the PR schedule (where the responserequirement increased after each reward obtained), control and mutant mice exhibited a comparable increase in their responding for food (Figure 6D left panel). Analysis of the breaking points (defined as the last ratio completed by the animal followed by 15 min during which no additional reward was earned) revealed no difference between controls and GR ${ }^{\mathrm{D} 1 \mathrm{Cre}}$ mice (Figure 6D right panel). While during initial instrumental training $\mathrm{GR}^{\mathrm{D} 1 \mathrm{Cre}}$ mice showed a trend toward a decrease in instrumental responses compared to controls, the opposite was rather observed during the last two sessions of PR. This set of data suggests that
GR in dopaminoceptive neurons does not modulate food reward responses.

\section{DISCUSSION}

In this study, we aimed at dissecting the modulatory role of GR within the meso-cortico-limbic dopamine system, on responses to amphetamine and food rewards. We showed that inactivation of GR gene in dopaminoceptive cells, but not in dopamine cells, decrease amphetamine-mediated locomotor sensitization and CPP, two behavioral features of psychostimulants. Along with these behavioral deficits, absence of GR in dopaminoceptive 

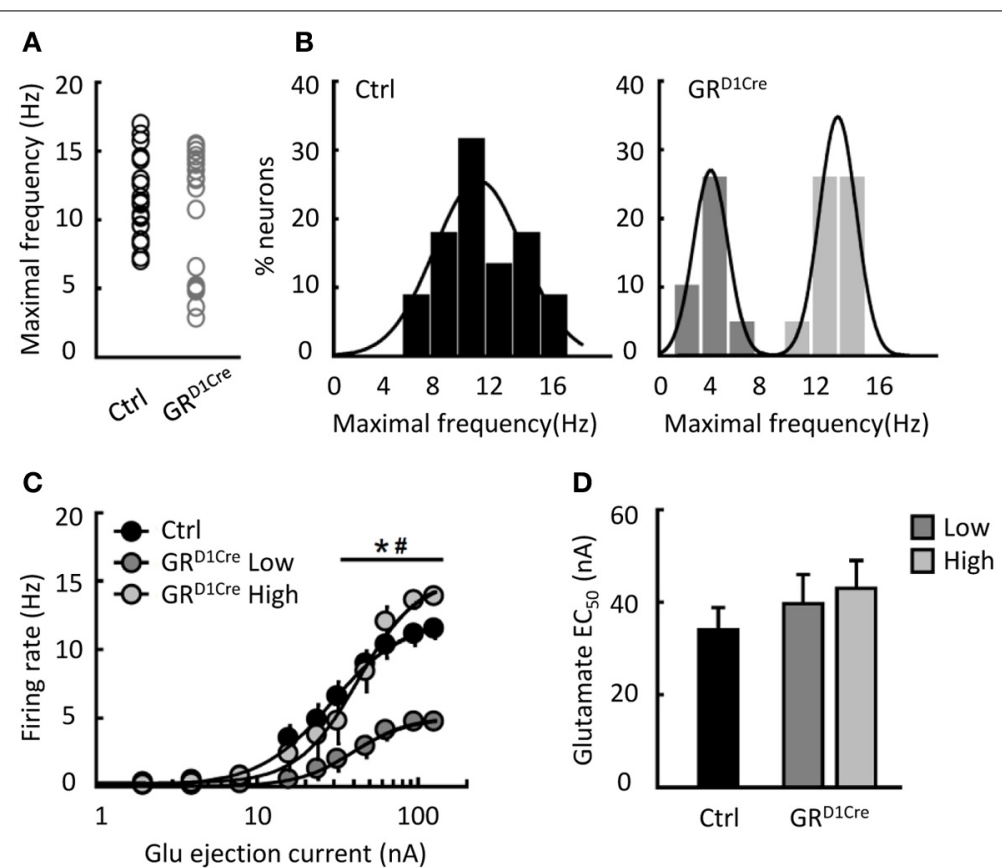

FIGURE 5 | Reduced glutamate induced-firing in a sub-population of NAc neurons in $\mathbf{G R}^{\mathbf{D} 1 \text { aCre }}$ mice. (A) Individual maximal frequencies reached after micro-iontophoretic application of glutamate in NAc neurons ( $n=22$ cells in 13 control mice and $n=20$ in $11 \mathrm{GR}^{\mathrm{D} 1 \mathrm{Cre}}$ mice). (B) The distribution of maximal frequencies after glutamate application was normal in control mice (Shapiro-Wilk test, $W=0.96, p=0.58$ ) and bimodally distributed in GR $R^{\mathrm{D} 1 \mathrm{Cre}}$ mice (Shapiro-Wilk test, $W=0.82, p<0.002$ ). (C)
Glutamate dose response in NAc neurons from control mice (black bars) and in the two populations of NAc neurons found in $\mathrm{GR}^{\mathrm{D} 1 \mathrm{Cre}}$ mice. Slow-firing neurons recorded in $\mathrm{GR}^{\mathrm{D} 1 \mathrm{Cre}}$ mice differed from the two other populations [dose population interaction $F_{(20,390)}=5.47, p<0.0001$ ]. $* P<0.001$ for $\mathrm{GR}^{\mathrm{D} 1 \mathrm{Cre}}$ slow vs. GR ${ }^{\mathrm{D} 1 \mathrm{Cre}}$ high, ${ }^{\#} P<0.001$ for $\mathrm{GR}^{\mathrm{D} 1 \mathrm{Cre}}$ slow vs. control. (D) The $\mathrm{EC}_{50}$ of the 3 populations of neurons did not differ $\left[F_{(2,39)}=0.72, p=0.49\right]$. cells decreased the post-synaptic response to amphetamine within the NAc as assessed by c-Fos immunostaining. These changes in behavioral and post-synaptic neuronal activation to amphetamine may involve abnormal glutamate transmission as mice deprived of GR in dopaminoceptive neurons showed a decrease in locomotor response to NMDA receptor antagonist MK801 and a decrease in neuronal response to intra-accumbal glutamate administration. These results extend our previous findings which showed that inactivation of GR in the same cell population dampens behavioral and molecular responses to cocaine, another psychostimulant drug (Ambroggi et al., 2009; Barik et al., 2010). These modulatory effects of GR appear to be selective to psychostimulants as neither morphine (Barik et al., 2010) nor food reward responses (the present study) are affected by the inactivation of GR gene in the meso-cortico-limbic dopamine system.

While a body of evidence suggest that stress reaction, as well as GCs, facilitate behavioral responses to amphetamine, the brain regions targeted by GCs actions remained to be identified. Furthermore, the determination of the receptor type involved is still a matter of debate. Although pharmacological antagonism of GR, using the antagonist RU486, has been shown to decrease amphetamine-induced locomotor sensitization without changing the acute locomotor response to the drug (De Vries et al., 1996), systemic administration of GR agonist dexamethasone decreased amphetamine induced hyperactivity (Capasso et al., 1996). These confounding results are however difficult to interpret as the RU486 is also a potent progesterone receptor antagonist (Cadepond et al., 1997), and dexamethasone, when injected systemically, is actively expelled from the brain compartment, hence substantially limiting its effects (Meijer et al., 1998). Systemic dexamethasone may have resulted in a depletion of endogenous GCs levels via the negative feedback exerted by activation of GR in the pituitary gland. The response to amphetamine has also been studied in a transgenic mouse model expressing a neurofilament promoter-driven antisense RNA complementary to a fragment of cDNA that codes for the mouse GR. In this model, GR mRNA levels are decreased by $50 \%$ on average in the brain (Pepin et al., 1992). An enhanced locomotor response to amphetamine in this model suggested that GR may decrease sensitivity to this drug (Cyr et al., 2001). However, disturbances in HPA axis function, including elevated levels of adrenocorticotropin hormone and GCs and a lack of diurnal variation in HPA axis activity may have led to confounding effects (Beaulieu et al., 1994). The fact that selective ablation of GR from dopamine neurons had no effect on behavioral responses to amphetamine is in coherence with the absence of effects we previously observed on behavioral responses to cocaine and on spontaneous firing of dopamine neurons (Ambroggi et al., 2009; Barik et al., 2010). We believe that the reduced behavioral responses to amphetamine observed in $\mathrm{GR}^{\mathrm{D} 1 \mathrm{Cre}}$ mice result from the absence of GR in dopaminoceptive neurons. Indeed, although expression of D1 


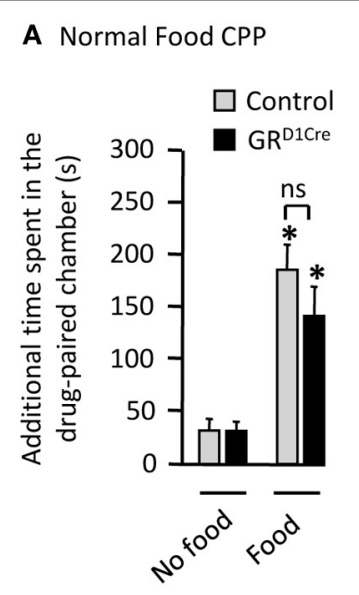

B

Palatable Food CPP

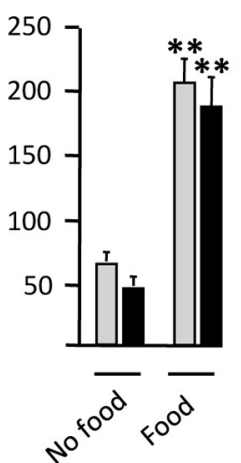

C Palatable Food, Fixed Ratio 1

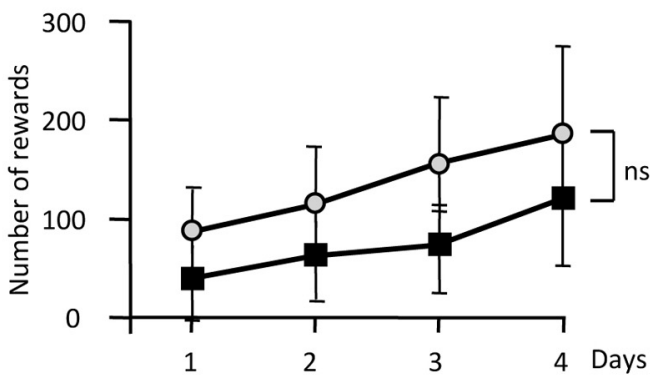

D Palatable Food, Progressive ratio
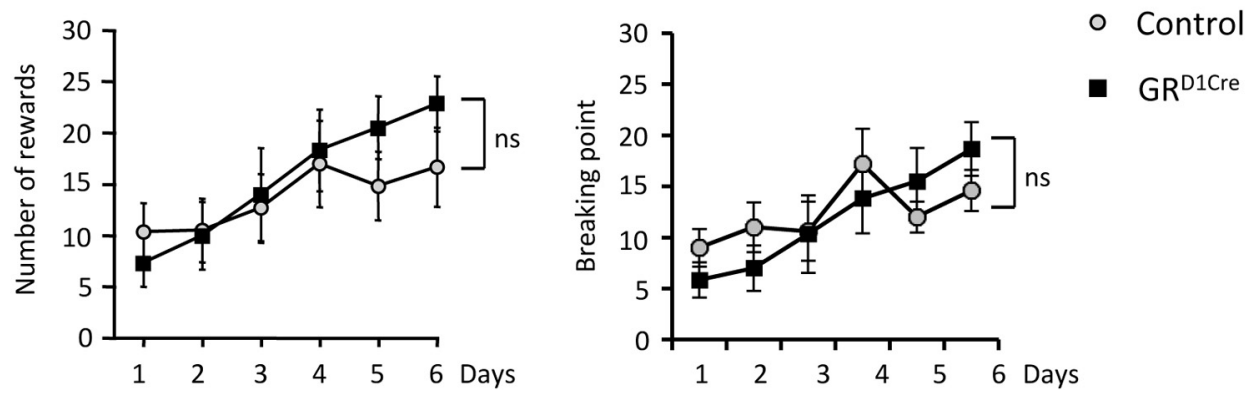

- Control

- GR $R^{\mathrm{D} 1 \mathrm{Cre}}$

FIGURE 6 | Unaltered responses to food reward in $\mathbf{G R}^{\mathbf{D} 1 \mathrm{Cre}}$ mice. CPP scores represent the time difference between post-conditioning and pre-conditioning phases that mice spent in the reward-paired chamber. (A) Control and GR ${ }^{\text {D1Cre }}$ mice show similar levels of CPP when normal chow pellet were use as a conditioning stimulus. Effect of Food $F_{(1,33)}=4.4$, $P<0.05$, but no effect of genotype $F_{(1,33)}=0.9, P>0.05$. (B) Similar responses were also obtained when control and $\mathrm{GR}^{\mathrm{D} 1 \mathrm{Cre}}$ mice were paired with palatable food, which significantly increased the time spent in the paired chamber $\left[F_{(1,35)}=45.8, P<0.001\right]$ regardless of the genotype $\left[F_{(1,35)}=0.9, P>0.05\right]$. (C) In operant chambers, both control and $\mathrm{GR}^{\mathrm{D} 1 \mathrm{Cre}}$ mice exhibited similar responses for palatable food reward either under a fixed ratio 1 schedule [no effect of genotype $F_{(1,40)}=0.8, P>0.05$ ], or (D) a more stringent progressive ratio schedule [no effect of genotype,

$\left.F_{(1,60)}=0.9, P>0.05\right]$. For CPP $n=8-12$ mice per group and for operant responding for palatable food $n=6$ mice per group. ns: non-significant $* P<0.05, * * P<0.01$. receptor have been reported in peripheral tissues, (Ozono et al., 1997) the potential GR gene recombination in the periphery in $\mathrm{GR}^{\mathrm{D} 1 \mathrm{cre}}$ mice does not alter HPA-axis activity (Ambroggi et al., 2009) and is unlikely to alter amphetamine metabolism.

Strikingly, GR in dopaminoceptive neurons appears to modulate behavioral responses to low ( $1 \mathrm{mg} / \mathrm{kg})$ but not high $(2 \mathrm{mg} / \mathrm{kg})$ doses of amphetamine. This effect has been observed for both locomotor sensitization and CPP. In rats, it was reported that the environmental changes in housing conditions, which differently shape the HPA axis, only affected the reinforcing properties of low doses of amphetamine, suggesting that the environment modifies the threshold for positive hedonic effects of amphetamine (Bardo et al., 2001; Green et al., 2002; Stairs et al., 2011). Altogether, these data suggest that stress-induced GCs release increases the sensitivity to reinforcing, rewarding, and sensitizing properties of amphetamine for moderate doses and this effect could be at least partially mediated through activation of GR within dopaminetargeted areas. In addition to these behavioral effects, we also observed a decrease in the induction of c-Fos by amphetamine specifically within the NAc of $\mathrm{GR}^{\mathrm{D} 1 \mathrm{Cre}}$ mice. An acute cocaine injection has been previously shown to predominantly (but not exclusively) induce c-Fos in D1-expressing medium spiny neurons (Bertran-Gonzalez et al., 2008). We might expect a similar pattern of induction in response to amphetamine. Despite the decreased neuronal response to amphetamine, their acute locomotor response was unaltered compared to controls. Such apparent contradiction can however be partially resolved. A previous study showed that complete absence of c-Fos in D1-expressing neurons, obtained by conditional gene inactivation, does not alter the marked locomotor response to an acute injection of the D1like agonist SKF81297. It also has no effect on the acute locomotor response to a moderate $(10 \mathrm{mg} / \mathrm{kg})$ dose of cocaine but does impair locomotor sensitization (Zhang et al., 2006). Thus, c-Fos induction in dopamine-innervated areas is not necessary to build an acute locomotor response to moderate doses of psychostimulant drugs but seems crucial for the development of sensitizing effects. In the present study we did not investigate for c-Fos induction after repeated injection of amphetamine. However, we 
have previously shown that repeated administration of cocaine leads to a sensitization of c-Fos mRNA induction specifically in the $\mathrm{CPu}$ and motor cortex and that this sensitization was abolished in mice lacking GR in the whole central nervous system (Deroche-Gamonet et al., 2003).

Decreased behavioral and post-synaptic responses to amphetamine observed in $\mathrm{GR}^{\mathrm{D} 1 \mathrm{Cre}}$ mice were unlikely due to alterations in post-synaptic dopamine D1-mediated signaling as these mice showed similar responses to dopamine D1-like receptor agonists SKF81297 compared to controls. In contrast, we showed that the absence of GR in dopaminoceptive neurons dampened locomotor responses to MK801, a NMDA receptor antagonist. Given that c-Fos induction by amphetamine is specifically dampened in the NAc, this suggests that glutamate neurotransmission could potentially be impaired within this brain region. This is confirmed by our electrophysiological data. In $\mathrm{GR}^{\mathrm{D} 1 \mathrm{Cr} e}$ mice, about half of NAc medium spiny neurons were found to be less reactive to glutamate while the remaining neurons had normal responses. Medium spiny neurons in both $\mathrm{CPu}$ and NAc can be segregated in two neuronal populations expressing either D1 or D2 dopamine receptors with some overlap between these two populations (Bertran-Gonzalez et al., 2010). The bimodal distribution could therefore be the result of this segregation. However, $\mathrm{GR}^{\mathrm{D} 1 \mathrm{Cre}}$ mice are likely to be recombined in both populations (Barik et al., 2013), potentially because of transient developmental expression of the D1 receptor. GR may differentially regulate glutamate reactivity in D1- or D2expressing neurons and future studies will be needed to directly test this hypothesis. The alteration of glutamate neurotransmission within the NAc could explain the decreased responses to psychostimulants, which also largely relies on glutamate transmission (Kalivas, 2000). A body of evidence suggests that GR can modulate glutamate transmission in the brain (Popoli et al., 2012). In addition, in a previous study, microarray and RT-qPCR revealed changes in the expression of NMDA receptor subunits and in AMPA/kainate signaling pathways within the striatum of $\mathrm{GR}^{\mathrm{D} 1 \mathrm{Cre}}$ mice (Barik et al., 2010). These changes could account for the alteration of glutamate neurotransmission in these mice.

This study, as well as our previous work, clearly demonstrate that the absence of GR in dopaminoceptive neurons diminish reinforcing, rewarding, and sensitizing effects of psychostimulants. As the same brain circuits are involved in behavioral responses to abused drugs and natural rewards, we also investigated the effect of inactivating GR within dopaminoceptive cells on the hedonic reactions to food reward (either regular chow or palatable food) in a CPP paradigm and on the willingness to expend effort to obtain a food reward in a progressive ratio task. Both meso-accumbens and nigro-striatal dopamine pathways have been involved in the modulation of motivation and decision-making processes essential to reach a goal (Schultz, 2006; Wise, 2008). Moreover, deficits in motivation are hallmark features of many psychiatric disorders including depression for which stress exposure is an important environmental risk factor. A recent study in rat showed that chronic stress exposure impairs the sensitivity to changes in outcome value and in response-outcome contingency suggesting that chronic stress exposure might induce deficits in reward expectation (DiasFerreira et al., 2009). Along with these deficits, structural changes in prefrontal areas and in the dorsal striatum have been observed suggesting that stress exposure may lead to goal-directed behavior impairments by altering cortico-striatal circuits (Dias-Ferreira et al., 2009). Interestingly, these results were mimicked by chronic GCs administration. Indeed, chronic GCs treatments have been shown to impair goal-directed response-outcome associations as well as motivation to obtain food reward in a PR schedule. On the other side, acute pharmacological blockade of GR only impaired response-outcome association sparing motivation (Gourley et al., 2012). Surprisingly, we did not find any difference between $\mathrm{GR}^{\mathrm{D} 1 \mathrm{Cre}}$ mice and control littermates in both CPP and PR tasks suggesting that GR in this cell population may not be necessary to modulate rewarding and reinforcing properties of food as it is for psychostimulant drugs. In $\mathrm{GR}^{\mathrm{D} 1 \mathrm{Cre}}$ mice, most of striatal and NAc neurons show an inactivation of GR. Indeed, GR ablation was observed in more than $85 \%$ of striatal neurons. However, within the cortex, only neurons located within deep layers (V/VI) exhibit a percentage of recombination comparable to that of striatal neurons, while most of neurons from upper layers still express GR (Barik et al., 2013). Thus, the effects of stress and GCs on goal-directed behavior and motivation might be rather mediated by an impact at the level of the PFC rather than the striatum or the NAc. Another possibility is that the inactivation of GR in dopaminoceptive neurons may protect from deleterious effects of chronic stress exposure rather than having an effect at basal stress levels. Further studies will be required to explore these hypotheses.

Our findings along with previous studies show that GR in dopaminoceptive neurons selectively modulates reinforcing, rewarding, and sensitizing properties of psychostimulant drugs such as cocaine and amphetamine. These effects seem mediated by alterations of integration of glutamate signaling within the striatum and NAc. On the other side, behavioral responses to food remained unchanged in the absence of GR within dopaminoceptive neurons. These results could be interesting in the context of the development of new medications able to decrease sensitivity to abused drugs while sparing general motivation for natural reinforcers.

\section{AUTHOR CONTRIBUTIONS}

Sébastien Parnaudeau, François Tronche, and Jacques Barik designed the study. Sébastien Parnaudeau, Frédéric Ambroggi, Marc Turiault, Marie-louise Dongelmans, Anne-Sophie Delbes, Céline Cansell, Serge Luquet, and Jacques Barik performed research. Sébastien Parnaudeau, Frédéric Ambroggi, Marc Turiault, Marie-louise Dongelmans, Pier-Vincenzo Piazza, Jacques Barik, and François Tronche analyzed the data. Sébastien Parnaudeau, Frédéric Ambroggi, François Tronche, and Jacques Barik wrote the manuscript.

\section{ACKNOWLEDGMENTS}

We thank staff from the IFR83 animal facility for assistance. This work was funded by the CNRS, the INSERM, the University Pierre et Marie Curie, the EU (STREP PheComp), the Agence Nationale de la Recherche (TIMMS grants), and 
the Mission Interministérielle de Lutte contre la Dépendance et la Toxicomanie. François Tronche's group is member of the LabEx BioPsy and the DHU PePSY, Sébastien Parnaudeau and Jacques Barik have been supported by the UPMC and the Collège de France (Sébastien Parnaudeau) and the Fondation pour la Recherche Médicale (Jacques Barik).

\section{REFERENCES}

Adam, T. C., and Epel, E. S. (2007). Stress, eating and the reward system. Physiol. Behav. 91, 449-458. doi: 10.1016/j.physbeh.2007.04.011

Ambroggi, F., Turiault, M., Milet, A., Deroche-Gamonet, V., Parnaudeau, S., Balado, E., et al. (2009). Stress and addiction: glucocorticoid receptor in dopaminoceptive neurons facilitates cocaine seeking. Nat. Neurosci. 12, 247-249. doi: 10.1038/nn.2282

Bamford, N. S., Zhang, H., Schmitz, Y., Wu, N. P., Cepeda, C., Levine, M. S., et al. (2004). Heterosynaptic dopamine neurotransmission selects sets of corticostriatal terminals. Neuron 42, 653-663. doi: 10.1016/S0896-6273(04)00265-X

Bardo, M. T., and Bevins, R. A. (2000). Conditioned place preference: what does it add to our preclinical understanding of drug reward? Psychopharmacology (Berl). 153, 31-43. doi: 10.1007/s002130000569

Bardo, M. T., Klebaur, J. E., Valone, J. M., and Deaton, C. (2001). Environmental enrichment decreases intravenous self-administration of amphetamine in female and male rats. Psychopharmacology (Berl). 155, 278-284. doi: $10.1007 / \mathrm{s} 002130100720$

Barik, J., Marti, F., Morel, C., Fernandez, S. P., Lanteri, C., Godeheu, G., et al. (2013). Chronic stress triggers social aversion via glucocorticoid receptor in dopaminoceptive neurons. Science 339, 332-335. doi: 10.1126/science.1226767

Barik, J., Parnaudeau, S., Saint Amaux, A. L., Guiard, B. P., Golib Dzib, J. F., Bocquet, O., et al. (2010). Glucocorticoid receptors in dopaminoceptive neurons, key for cocaine, are dispensable for molecular and behavioral morphine responses. Biol. Psychiatry 68, 231-239. doi: 10.1016/j.biopsych.2010.03.037

Beaulieu, S., Rousse, I., Gratton, A., Barden, N., and Rochford, J. (1994). Behavioral and endocrine impact of impaired type II glucocorticoid receptor function in a transgenic mouse model. Ann. N.Y. Acad. Sci. 746, 388-391. doi: 10.1111/j.17496632.1994.tb39263.x

Bertran-Gonzalez, J., Bosch, C., Maroteaux, M., Matamales, M., Herve, D., Valjent, E., et al. (2008). Opposing patterns of signaling activation in dopamine D1 and D2 receptor-expressing striatal neurons in response to cocaine and haloperidol. J. Neurosci. 28, 5671-5685. doi: 10.1523/JNEUROSCI.1039-08.2008

Bertran-Gonzalez, J., Herve, D., Girault, J. A., and Valjent, E. (2010). What is the degree of segregation between striatonigral and striatopallidal projections? Front. Neuroanat. 4:136. doi: 10.3389/fnana.2010.00136

Cadepond, F., Ulmann, A., and Baulieu, E. E. (1997). RU486 (mifepristone): mechanisms of action and clinical uses. Annu. Rev. Med. 48, 129-156. doi: 10.1146/annurev.med.48.1.129

Capasso, A., Di Giannuario, A., Loizzo, A., Pieretti, S., and Sorrentino, L. (1996). Actinomycin D blocks the reducing effect of dexamethasone on amphetamine and cocaine hypermotility in mice. Gen. Pharmacol. 27, 707-712. doi: 10.1016/0306-3623(95)02077-2

Castonguay, T. W. (1991). Glucocorticoids as modulators in the control of feeding. Brain Res. Bull. 27, 423-428. doi: 10.1016/0361-9230(91)90136-8

Corvol, J. C., Valjent, E., Pascoli, V., Robin, A., Stipanovich, A., Luedtke, R. R., et al. (2007). Quantitative changes in Galphaolf protein levels, but not D1 receptor, alter specifically acute responses to psychostimulants. Neuropsychopharmacology 32, 1109-1121. doi: 10.1038/sj.npp.1301230

Cyr, M., Morissette, M., Barden, N., Beaulieu, S., Rochford, J., and Di Paolo, T. (2001). Dopaminergic activity in transgenic mice underexpressing glucocorticoid receptors: effect of antidepressants. Neuroscience 102, 151-158. doi: 10.1016/S0306-4522(00)00444-9

Dallman, M. F., la Fleur, S. E., Pecoraro, N. C., Gomez, F., Houshyar, H., and Akana, S. F. (2004). Minireview: glucocorticoids-food intake, abdominal obesity, and wealthy nations in 2004. Endocrinology 145, 2633-2638. doi: 10.1210/en.20040037

Deroche, V., Marinelli, M., Maccari, S., Le Moal, M., Simon, H., and Piazza, P. V. (1995). Stress-induced sensitization and glucocorticoids. I. Sensitization of dopamine-dependent locomotor effects of amphetamine and morphine depends on stress-induced corticosterone secretion. J. Neurosci. 15, 7181-7188.
Deroche-Gamonet, V., Sillaber, I., Aouizerate, B., Izawa, R., Jaber, M., Ghozland, S., et al. (2003). The glucocorticoid receptor as a potential target to reduce cocaine abuse. J. Neurosci. 23, 4785-4790.

De Vries, T. J., Schoffelmeer, A. N., Tjon, G. H., Nestby, P., Mulder, A. H., and Vanderschuren, L. J. (1996). Mifepristone prevents the expression of long-term behavioural sensitization to amphetamine. Eur. J. Pharmacol. 307, R3-R4. doi: 10.1016/0014-2999(96)00308-1

Dias-Ferreira, E., Sousa, J. C., Melo, I., Morgado, P., Mesquita, A. R., Cerqueira, J. J., et al. (2009). Chronic stress causes frontostriatal reorganization and affects decision-making. Science 325, 621-625. doi: 10.1126/science.1171203

Di Chiara, G., and Imperato, A. (1988). Drugs abused by humans preferentially increase synaptic dopamine concentrations in the mesolimbic system of freely moving rats. Proc. Natl. Acad. Sci. U.S.A. 85, 5274-5278. doi: 10.1073/pnas.85.14.5274

Gourley, S. L., Swanson, A. M., Jacobs, A. M., Howell, J. L., Mo, M., Dileone, R. J., et al. (2012). Action control is mediated by prefrontal BDNF and glucocorticoid receptor binding. Proc. Natl. Acad. Sci. U.S.A. 109, 20714-20719. doi: 10.1073/pnas. 1208342109

Green, T. A., Gehrke, B. J., and Bardo, M. T. (2002). Environmental enrichment decreases intravenous amphetamine self-administration in rats: dose-response functions for fixed- and progressive-ratio schedules. Psychopharmacology (Berl). 162, 373-378. doi: 10.1007/s00213-002-1134-y

Groeneweg, F. L., Karst, H., de Kloet, E. R., and Joels, M. (2011). Rapid nongenomic effects of corticosteroids and their role in the central stress response. J. Endocrinol. 209, 153-167. doi: 10.1530/JOE-10-0472

Hernandez, L., and Hoebel, B. G. (1988). Food reward and cocaine increase extracellular dopamine in the nucleus accumbens as measured by microdialysis. Life Sci. 42, 1705-1712. doi: 10.1016/0024-3205(88)90036-7

Kalivas, P. W. (2000). A role for glutamate transmission in addiction to psychostimulants. Addict. Biol. 5, 325-329. doi: 10.1111/j.1369-1600.2000.tb00199.x

Kelley, A. E. (2004). Memory and addiction: shared neural circuitry and molecular mechanisms. Neuron 44, 161-179. doi: 10.1016/j.neuron.2004.09.016

Kelley, A. E., and Berridge, K. C. (2002). The neuroscience of natural rewards: relevance to addictive drugs. J. Neurosci. 22, 3306-3311. doi: 20026361

Kish, L. J., Palmer, M. R., and Gerhardt, G. A. (1999). Multiple single-unit recordings in the striatum of freely moving animals: effects of apomorphine and D-amphetamine in normal and unilateral 6-hydroxydopamine-lesioned rats. Brain Res. 833, 58-70. doi: 10.1016/S0006-8993(99)01496-1

Lemberger, T., Parlato, R., Dassesse, D., Westphal, M., Casanova, E., Turiault, M., et al. (2007). Expression of Cre recombinase in dopaminoceptive neurons. BMC Neurosci. 8:4. doi: 10.1186/1471-2202-8-4

Le Minh, N., Damiola, F., Tronche, F., Schutz, G., and Schibler, U. (2001). Glucocorticoid hormones inhibit food-induced phase-shifting of peripheral circadian oscillators. EMBO J. 20, 7128-7136. doi: 10.1093/emboj/20.24.7128

Mallet, N., Le Moine, C., Charpier, S., and Gonon, F. (2005). Feedforward inhibition of projection neurons by fast-spiking GABA interneurons in the rat striatum in vivo. J. Neurosci. 25, 3857-3869. doi: 10.1523/JNEUROSCI.502704.2005

Marinelli, M., and Piazza, P. V. (2002). Interaction between glucocorticoid hormones, stress and psychostimulant drugs. Eur. J. Neurosci. 16, 387-394. doi: 10.1046/j.1460-9568.2002.02089.x

Marinelli, M., Rouge-Pont, F., De Jesus-Oliveira, C., Le Moal, M., and Piazza, P. V. (1997). Acute blockade of corticosterone secretion decreases the psychomotor stimulant effects of cocaine. Neuropsychopharmacology 16, 156-161. doi 10.1016/S0893-133X(96)00169-8

Meijer, O. C., de Lange, E. C., Breimer, D. D., de Boer, A. G., Workel, J. O., and de Kloet, E. R. (1998). Penetration of dexamethasone into brain glucocorticoid targets is enhanced in mdr1A P-glycoprotein knockout mice. Endocrinology 139, 1789-1793. doi: 10.1210/endo.139.4.5917

Moratalla, R., Elibol, B., Vallejo, M., and Graybiel, A. M. (1996). Networklevel changes in expression of inducible Fos-Jun proteins in the striatum during chronic cocaine treatment and withdrawal. Neuron 17, 147-156. doi: 10.1016/S0896-6273(00)80288-3

Nicola, S. M., Surmeier, J., and Malenka, R. C. (2000). Dopaminergic modulation of neuronal excitability in the striatum and nucleus accumbens. Annu. Rev. Neurosci. 23, 185-215. doi: 10.1146/annurev.neuro.23.1.185

Ozono, R., O'Connell, D. P., Wang, Z. Q., Moore, A. F., Sanada, H., Felder, R. A., et al. (1997). Localization of the dopamine D1receptor protein in the human heart and kidney. Hypertension 30, 725-729. doi: 10.1161/01.HYP.30.3.725 
Pascoli, V., Besnard, A., Herve, D., Pages, C., Heck, N., Girault, J. A., et al. (2011). Cyclic adenosine monophosphate-independent tyrosine phosphorylation of NR2B mediates cocaine-induced extracellular signal-regulated kinase activation. Biol. Psychiatry 69, 218-227. doi: 10.1016/j.biopsych.2010.08.031

Pepin, M. C., Pothier, F., and Barden, N. (1992). Impaired type II glucocorticoidreceptor function in mice bearing antisense RNA transgene. Nature 355, 725-728. doi: 10.1038/355725a0

Popoli, M., Yan, Z., McEwen, B. S., and Sanacora, G. (2012). The stressed synapse: the impact of stress and glucocorticoids on glutamate transmission. Nat. Rev. Neurosci. 13, 22-37. doi: 10.1038/nrn3138

Qi, C., Zou, H., Zhang, R., Zhao, G., Jin, M., and Yu, L. (2008). Age-related differential sensitivity to MK-801-induced locomotion and stereotypy in C57BL/6 mice. Eur. J. Pharmacol. 580, 161-168. doi: 10.1016/j.ejphar.2007.07.071

Schultz, W. (2006). Behavioral theories and the neurophysiology of reward. Annu. Rev. Psychol. 57, 87-115. doi: 10.1146/annurev.psych.56.091103.070229

Sinha, R. (2001). How does stress increase risk of drug abuse and relapse? Psychopharmacology (Berl). 158, 343-359. doi: 10.1007/s002130100917

Sinha, R., Garcia, M., Paliwal, P., Kreek, M. J., and Rounsaville, B. J. (2006). Stress-induced cocaine craving and hypothalamic-pituitary-adrenal responses are predictive of cocaine relapse outcomes. Arch. Gen. Psychiatry 63, 324-331. doi: 10.1001/archpsyc.63.3.324

Stairs, D. J., Prendergast, M. A., and Bardo, M. T. (2011). Environmentalinduced differences in corticosterone and glucocorticoid receptor blockade of amphetamine self-administration in rats. Psychopharmacology (Berl). 218, 293-301. doi: 10.1007/s00213-011-2448-4

Torres, S. J., and Nowson, C. A. (2007). Relationship between stress, eating behavior, and obesity. Nutrition 23, 887-894. doi: 10.1016/j.nut.2007.08.008

Turiault, M., Parnaudeau, S., Milet, A., Parlato, R., Rouzeau, J. D., Lazar, M., et al. (2007). Analysis of dopamine transporter gene expression pattern - generation of DAT-iCre transgenic mice. FEBS J. 274, 3568-3577. doi: 10.1111/j.17424658.2007.05886.x
Vanderschuren, L. J., and Pierce, R. C. (2010). Sensitization processes in drug addiction. Curr. Top. Behav. Neurosci. 3, 179-195. doi: 10.1007/7854_ 2009_21

White, F. J. (1996). Synaptic regulation of mesocorticolimbic dopamine neurons. Annu. Rev. Neurosci. 19, 405-436. doi: 10.1146/annurev.ne.19.030196.002201

Wise, R. A. (2008). Dopamine and reward: the anhedonia hypothesis 30 years on. Neurotox. Res. 14, 169-183. doi: 10.1007/BF03033808

Zhang, J., Zhang, L., Jiao, H., Zhang, Q., Zhang, D., Lou, D., et al. (2006). c-Fos facilitates the acquisition and extinction of cocaine-induced persistent changes. J. Neurosci. 26, 13287-13296. doi: 10.1523/JNEUROSCI.3795-06.2006

Conflict of Interest Statement: The authors declare that the research was conducted in the absence of any commercial or financial relationships that could be construed as a potential conflict of interest.

Received: 30 October 2013; accepted: 23 January 2014; published online: 12 February 2014.

Citation: Parnaudeau S, Dongelmans M-L, Turiault M, Ambroggi F, Delbes A-S, Cansell C, Luquet S, Piazza P-V, Tronche F and Barik J (2014) Glucocorticoid receptor gene inactivation in dopamine-innervated areas selectively decreases behavioral responses to amphetamine. Front. Behav. Neurosci. 8:35. doi: 10.3389/fnbeh. 2014.00035

This article was submitted to the journal Frontiers in Behavioral Neuroscience. Copyright (c) 2014 Parnaudeau, Dongelmans, Turiault, Ambroggi, Delbes, Cansell, Luquet, Piazza, Tronche and Barik. This is an open-access article distributed under the terms of the Creative Commons Attribution License (CCBY). The use, distribution or reproduction in other forums is permitted, provided the original author(s) or licensor are credited and that the original publication in this journal is cited, in accordance with accepted academic practice. No use, distribution or reproduction is permitted which does not comply with these terms. 